\title{
Epidemiological investigation of 264 sporadic cases of ruptured cerebral aneurysm at a single institution in southwest China
}

This article was published in the following Dove Press journal:

Neuropsychiatric Disease and Treatment

I July 2015

Number of times this article has been viewed

\author{
Heng Liu' \\ Tijiang Zhang' \\ Song Jiao ${ }^{2}$ \\ Bangguo $\mathrm{Li}^{\prime}$ \\ Jing Guan' \\ Yi-Xiang J Wang ${ }^{3}$ \\ 'Department of Radiology, \\ ${ }^{2}$ Cerebrovascular Diseases Clinic, \\ Affiliated Hospital of Zunyi Medical \\ University, Zunyi, Guizhou Province, \\ ${ }^{3}$ Department of Imaging and \\ Interventional Radiology, Chinese \\ University of Hong Kong, Prince \\ of Wales Hospital, Shatin, New \\ Territories, Hong Kong SAR, People's \\ Republic of China
}

Background: The purpose of this study was to investigate the epidemiology of sporadic ruptured cerebral aneurysm in the Chinese population.

Methods: We retrospectively analyzed the medical records of 264 consecutive Chinese patients admitted to the Affiliated Hospital of Zunyi Medical University of Guizhou Province in Southwest China between December 2012 and March 2015 for spontaneous subarachnoid hemorrhage due to a ruptured cerebral artery aneurysm.

Results: The study population comprised 171 females and 93 males with a median age of 50 (range 5-76) years. The female to male ratio was 1.84:1. For both males and females, aneurysm rupture was most common in the 40-49-year age group (34.5\%). Most of the ruptured aneurysms were in the size range of $2-5 \mathrm{~mm}(47.2 \%)$, followed by $5-10 \mathrm{~mm}$ (43.8\%). Ruptured aneurysms occurred most often in the posterior communicating artery $(36.6 \%)$ or the anterior communicating artery $(25.7 \%)$. There were more cases of anterior communicating artery aneurysm on the left side (53 [Left side] $/ 16$ [Right side] $=3.31, P<0.001)$ and slightly more cases of posterior communicating artery aneurysm on the right side (54 [Right side] $/ 44$ [Left side] $=1.23, P>0.05$ ).

Conclusion: This study provides valuable information on the epidemiology of ruptured cerebral aneurysm in the Chinese population.

Keywords: cerebral aneurysm, rupture, subarachnoid hemorrhage, Chinese population, epidemiology

\section{Introduction}

Ruptured cerebral aneurysm is the most common cause of subarachnoid hemorrhage (SAH), and is associated with significant morbidity and mortality. It is a serious form of intracranial hemorrhage that, even with the best available medical care, leaves a majority of its victims dead or severely disabled. It is less common than other forms of intracranial hemorrhage, but tends to affect younger people and so imposes a disproportionally high burden in terms of years of productive life lost. The incidence of SAH in Western populations is about 9-15/100,000 persons per year. ${ }^{1-3}$ About $80 \%$ of affected patients have radiological evidence of a ruptured aneurysm. ${ }^{4}$ The prevalence of asymptomatic intracranial aneurysm is estimated to be about $1.8 \%-2 \%{ }^{5,6}$ The epidemiology of cerebral aneurysm in Western populations is well reported in the literature..$^{5-9}$ Some studies have attempted to determine whether there is a critical size at which an aneurysm is likely to rupture and thus warrant treatment. ${ }^{10}$ It has been considered that site and patient age, as well as lesion size, may affect the risk of rupture of a cerebral aneurysm. ${ }^{11}$ Rinkel et al reported an annual rupture risk of $1.9 \%$ in Western populations. ${ }^{5,12}$ It has also been reported that there is a higher incidence of rupture of cerebral aneurysm in Japanese patients. ${ }^{12}$ An annual risk of cerebral 
aneurysm rupture of $2.7 \%$ has been reported in Japan, and this is relatively high compared with reports from Europe and North America.

Unlike the available data for Caucasian and Japanese populations, ${ }^{1-15}$ few studies describing the epidemiology of cerebral aneurysm in the Chinese population have been published. ${ }^{16-18}$ Recently, Zhao et al reported a retrospective analysis of 1,256 sporadic cases of ruptured cerebral aneurysm at a single institution in northern China. ${ }^{19}$ One of the coauthors of the present paper also coauthored that report. ${ }^{19}$ The purpose of the current study was to review the demographic patterns of sporadic ruptured cerebral aneurysm at one medical institution in southwest China. The results from this study will add to the knowledge of sporadic ruptured cerebral aneurysm in the Chinese population, and help to better understand the population differences. ${ }^{19,20}$

\section{Patients and methods}

This was a retrospective study of 264 consecutive Chinese patients admitted to the Affiliated Hospital of Zunyi Medical University, Guizhou Province, southwest China, between December 2012 and March 2015 for spontaneous SAH due to a ruptured cerebral artery aneurysm. The data analyzed in this study were extracted from the medical records held at the hospital. The institutional review board approved this retrospective analysis. The patients included 171 females and 93 males, with a median age of 50 (mean 51, standard deviation 11.1, range 5-76) years. SAH was initially diagnosed by brain computed tomography, and digital subtraction angiography (DSA) followed, SAH was confirmed to be due to cerebral aneurysm. In 163 cases, information on the size of the aneurysm was given categorically as microscopic ( $\leq 3 \mathrm{~mm})$, small $(<5 \mathrm{~mm})$, middle-sized $(5 \leq /<15 \mathrm{~mm})$, and large ( $\geq 15 \mathrm{~mm}$ ). The size of the ruptured aneurysm was measured by a specialist physician at the time of diagnosis in 25 male and 64 female patients. These measurements took place in the later stage of the study period, and were done using digital subtraction angiography, with the largest diameter measured through the long axis of the aneurysm, as described previously. ${ }^{8,18,19}$ Seven patients had multiple aneurysms, and the specific aneurysm responsible for the rupture could not be determined reliably from the medical records.

\section{Statistical analysis}

The statistical analysis was performed with Statistical Package for the Social Sciences version 14.0 for Windows (SPSS Inc., Chicago, IL, USA). Group comparisons were performed using the Student's $t$-test for normally distributed continuous variables or the Mann-Whitney $U$-test for other continuous variables. Contingency tables were analyzed using Fisher's Exact test for dichotomized variables or $\chi^{2}$ statistics. $P<0.05$ was considered to be statistically significant.

\section{Results \\ Sex characteristics in patients with ruptured cerebral aneurysm}

The study population included 264 patients comprising 171 females and 93 males, with a female to male ratio of 1.84:1, indicating that females had a higher incidence of cerebral aneurysm rupture than males $(P<0.001$, Table 1$)$. The female to male ratio was $1.5: 1$ in patients younger than 40 years, and decreased further to 1.21:1 for patients younger than 35 years, indicating that the relative incidence of males with cerebral aneurysm rupture tended to be higher in younger patients (Table 1).

\section{Age characteristics in patients with ruptured cerebral aneurysm}

The age distribution of the 264 cases is shown in Figure 1. For both males and females, aneurysm rupture was most common at the age of 40-49 years. Some subjects suffered a ruptured aneurysm before the age of 30 years $(n=6,2.4 \%)$ and some before the age of 20 years $(n=2,0.8 \%)$. The mean age of the male patients was lower than that of the female patients $(49.7 \pm 12.1$ years versus $52.7 \pm 10.5$ years, respectively, $P=0.035)$.

\section{Size characteristics of ruptured cerebral aneurysm}

In 225 patients, information on size of the aneurysm was given categorically as microscopic, small, medium, or large (Table 2). In 89 patients for whom aneurysm measurement was performed, the mean ruptured aneurysm size was $5.93 \pm 3.86$ (median 5.01) mm, being 6.48 \pm 4.28 (median 5.74) $\mathrm{mm}$ in males and $5.72 \pm 3.70$ (median 4.67 ) $\mathrm{mm}$ in females (Figure 2). Ruptured aneurysms were mostly in the size region of $2-5 \mathrm{~mm}(47.2 \%)$ or $5-10 \mathrm{~mm}(43.8 \%)$. The difference in size of the ruptured aneurysm was not significant between males and females $(P=0.18)$.

Table I Female to male ratio in patients with ruptured cerebral aneurysm

\begin{tabular}{|c|c|c|c|c|}
\hline & Female & Male & $\begin{array}{l}\text { Female/ } \\
\text { male ratio }\end{array}$ & $P$-value \\
\hline Total patient population $(n=264)$ & 171 & 93 & 1.84 & $<0.001$ \\
\hline Patients $\leq 39$ years $(n=31)$ & 19 & 12 & 1.50 & 0.273 \\
\hline Patients $\leq 34$ years $(\mathrm{n}=\mathrm{I} \mathrm{I})$ & 6 & 5 & 1.20 & 0.763 \\
\hline
\end{tabular}




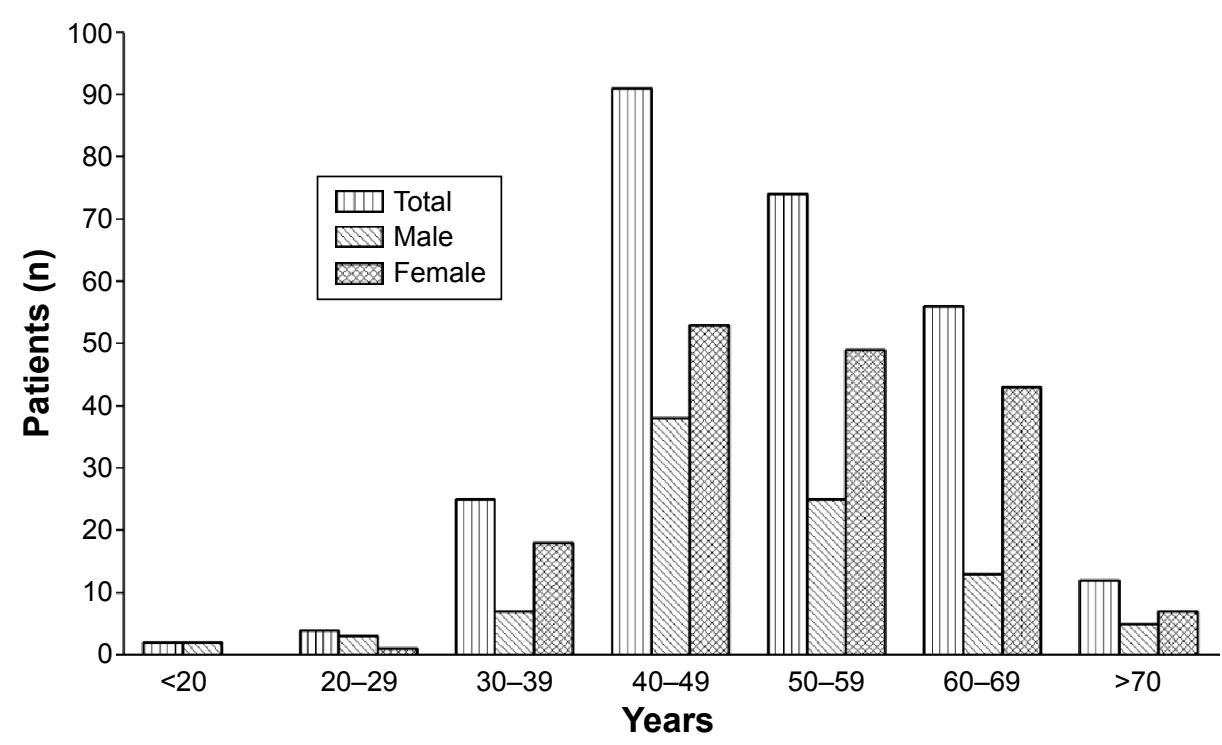

Figure I Age distribution of 264 cases with ruptured cerebral aneurysm.

\section{Location of cerebral aneurysm}

Data on location of the cerebral aneurysms are presented in Table 3. Cerebral aneurysm occurred in the anterior circulation in $96.6 \%$ of cases, with $3.4 \%$ occurring in the posterior circulation. Aneurysms most commonly occurred in the posterior communicating artery (PcoA, 36.6\%) and in the anterior communicating artery (AcoA, 25.7\%). Notably, there were more cases of AcoA aneurysm on the left side (53 [Left side] $/ 16$ [Right side] $=3.31, P<0.001)$ and more cases of PcoA aneurysm on the right side (54 [Right side]/44[Left side]=1.23), but the difference was not statistically significant.

\section{Characteristics of multiple cerebral aneurysms}

Seven patients $(2.7 \%)$ in this cohort had multiple cerebral aneurysms, with six having two aneurysms and one having three aneurysms (Table 4). Three patients had mirrored aneurysms, ie, aneurysms distributed both on the right side and the left side in a mirrored manner. ${ }^{19}$ All subjects with multiple cerebral aneurysms were female, and the PcoA was the most common site.

\section{Discussion}

The patients in this study cohort ranged in age from 5 to 76 years, with a mean age of 51 years, which was slightly

Table 2 Category classification of 225 patients with ruptured cerebral aneurysm

\begin{tabular}{lllll}
\hline Microscopic & Small & Medium & Large & Total \\
\hline$\leq 3 \mathrm{~mm}$ & $<5 \mathrm{~mm}$ & $5 \mathrm{~mm} \leq /<15 \mathrm{~mm} \geq 15 \mathrm{~mm}$ & \\
$49(21.8 \%)$ & $86(38.2 \%)$ & $75(33.3 \%)$ & $15(6.7 \%)$ & $225(100 \%)$ \\
\hline
\end{tabular}

younger than the mean age of 53.9 years in our previous report, ${ }^{19}$ and much younger than the mean age of 59 years reported by an earlier study of 267 Chinese patients in Hong Kong. ${ }^{18}$ Weir et al reported that the average age of 945 patients with ruptured aneurysms in their database was 46 years. ${ }^{11}$ In a study by Aarhus et al the median patient age was 50.9 years. ${ }^{21}$ Like in the Hong Kong study ${ }^{18}$ and consistent with our own previous report, ${ }^{19}$ males presented with ruptured cerebral aneurysm at a younger mean age (49.7 \pm 12.1 years) than females $(52.7 \pm 10.5$ years, $P=0.035)$. This observation has also been made in the Western literature. Aarhus et $\mathrm{al}^{21}$ reported that male patients were younger than female patients (mean 48.2 years versus 53.8 years). This difference in peak age of incidence may partially be attributed to the differences in lifestyle between men and women. A female predominance in patients with ruptured cerebral aneurysm has been reported in studies from the West (female to male ratio 2.86:1), ${ }^{10}$ Japan (female to male ratio 1.46:1), ${ }^{22}$ and Taiwan (female to male ratio 1.47:1). ${ }^{17}$ Similar to our previous series, which had a female to male ratio of 1.7:1, the current study shows a female to male ratio of 1.84:1. Also in line with our previous research, the current study shows that this female predominance becomes weaker in younger patients (Table 1). The Hong Kong study demonstrated a trend of larger ruptured aneurysms in men (mean size $6.3 \mathrm{~mm}$ ) than in women (mean size $5.6 \mathrm{~mm}$ ); however, this difference was not statistically significant. Our previous study also found that males had a slightly larger mean aneurysm size $(6.17 \mathrm{~mm})$ than females $(5.91 \mathrm{~mm})$, but again the difference was not statistically significant. ${ }^{19}$ In the current study, for the 89 patients in whom aneurysm 

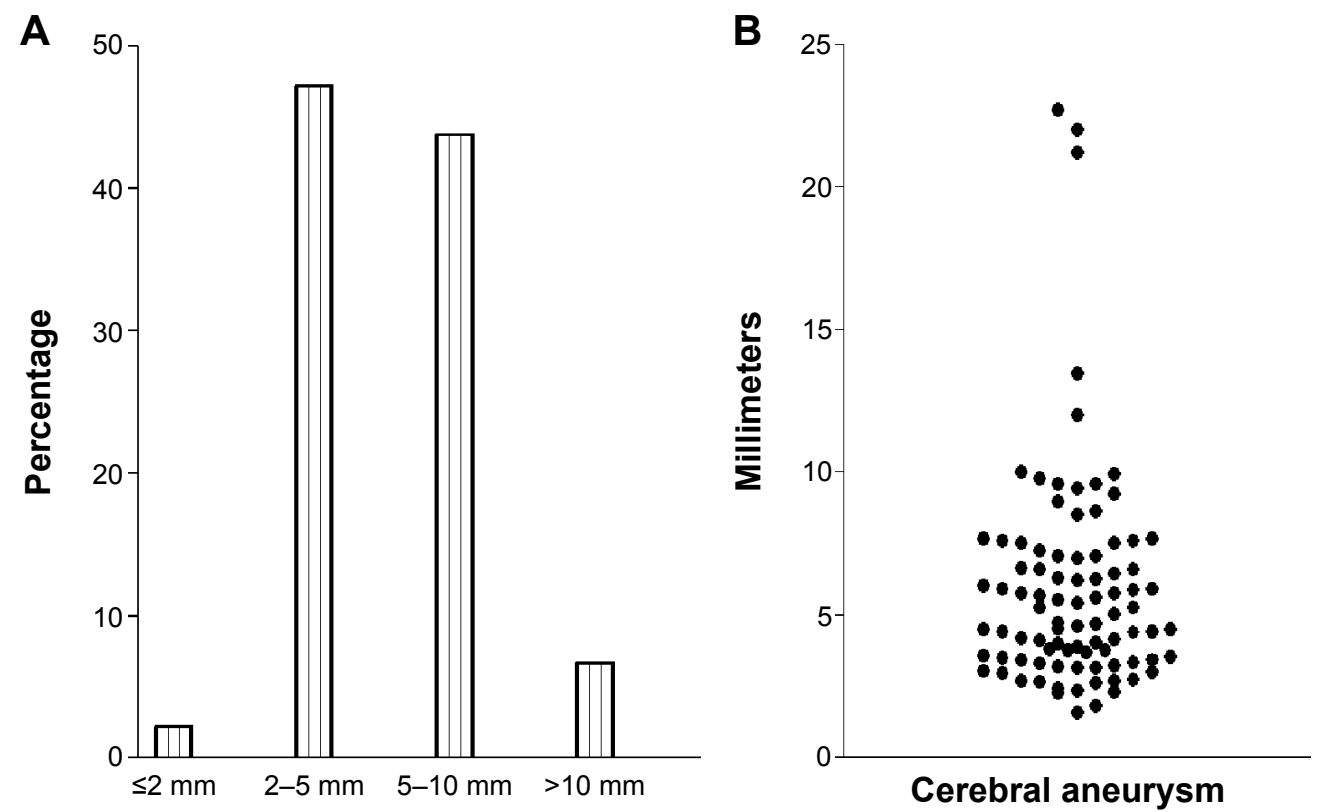

Figure 2 Size distribution of 89 cases with ruptured cerebral aneurysm and diameter measurement. (A) Categorical measurement (B) Continuous numerical measurement.

size was measured, the mean size of the ruptured aneurysm was $6.48 \pm 4.28$ (median 5.74) $\mathrm{mm}$ for males and 5.72 \pm 3.70 (median 4.67) $\mathrm{mm}$ for females, but again statistical significance was not reached.

Many series, including the present one, have reported that the majority of ruptured aneurysms are less than $10 \mathrm{~mm}$ in diameter. In our previous study, $90.6 \%$ of patients had rupture of aneurysms that were $\leq 10 \mathrm{~mm}$ in size; ${ }^{19} 50.9 \%$ of the patients had rupture of aneurysms $\leq 5 \mathrm{~mm}$ in size. ${ }^{19}$ In this series, ruptured aneurysms were mostly in the region of $2-5 \mathrm{~mm}(47.2 \%)$ or 5-10 mm (43.8\%). A previous study in the Hong Kong Chinese population also demonstrated that $64 \%$ had aneurysms of size $5 \mathrm{~mm}$ or less. ${ }^{18}$ This is different from findings in the Western and Japanese populations, where a lower proportion of ruptured cerebral aneurysms $5 \mathrm{~mm}$ or less in size has been reported. ${ }^{8,22-26}$ Kassel and Torner investigated 1,092 patients with $\mathrm{SAH}$ and reported that $71 \%$ of aneurysms were less than $10 \mathrm{~mm}$ in diameter and $13 \%$ were less than $5 \mathrm{~mm}$ in diameter. ${ }^{26}$ Mozoi et al found that the frequency distribution of the diameters of ruptured aneurysms increased sharply from $4 \mathrm{~mm}$ to a peak at $7 \mathrm{~mm}$ and decreased gradually thereafter. ${ }^{27}$ It is possible that aneurysms do not grow progressively once they form, but probably either rupture or stabilize, and that very elderly patients are at a reduced risk of rupture of aneurysms of the same size compared with patients who are younger. ${ }^{11}$ Longitudinal studies with repeated measurement of aneurysm size using noninvasive methods such as magnetic resonance angiography are needed to confirm this finding.

While some studies have classified PcoA as part of the posterior circulation, ${ }^{28}$ the $\mathrm{PcoA}$ connects the posterior and anterior cerebral circulations, and almost all of the aneurysms that affect it arise at the anterior circulation end, so the PcoA is usually considered part of the anterior circulation. ${ }^{29}$ In our study, we also

Table 3 Location of cerebral aneurysms

\begin{tabular}{|c|c|c|c|c|c|c|c|c|}
\hline \multirow[t]{4}{*}{ Anterior circulation } & L ICA & L MCA & L ACA & L AcoA & AcoA & L PcoA & L distant branch & Subtotal \\
\hline & 19 & 17 & 14 & 53 & 3 & 44 & 4 & 154 \\
\hline & R ICA & R MCA & R ACA & $R A c o A$ & & R PcoA & R distant branch & \\
\hline & 9 & 18 & 4 & 16 & & 54 & 4 & 105 \\
\hline Subtotal $(R+L)$ & 28 & 35 & 18 & 69 & 3 & 98 & 8 & 259 \\
\hline \multirow[t]{4}{*}{ Posterior circulation } & LVA & BA & L PCA & L distant branch & & & & \\
\hline & I & 2 & I & I & & & & 5 \\
\hline & R VA & & R PCA & $\mathrm{R}$ distant branch & & & & \\
\hline & 0 & & I & 3 & & & & 3 \\
\hline Subtotal $(R+L)$ & I & 2 & 2 & 4 & & & & 9 \\
\hline
\end{tabular}

Abbreviations: L, right; R, right; ICA, internal carotid artery (including any aneurysm located in the intracranial portion of ICA); MCA, middle cerebral artery; ACA, anterior cerebral artery; AcoA, anterior communicating artery; PcoA, posterior communicating artery; VA, vertebral artery; BA, basilar artery; PCA, posterior cerebral artery. 
Table 4 Characteristics of seven cases with multiple cerebral aneurysms

\begin{tabular}{|c|c|c|c|c|c|c|c|c|c|c|}
\hline Sex & $\begin{array}{l}\text { Age, } \\
\text { years }\end{array}$ & $\begin{array}{l}\text { Number of } \\
\text { aneurysms }\end{array}$ & $\begin{array}{l}\text { Mirrored } \\
\text { aneurysms }\end{array}$ & L ICA & R ICA & R MCA & AcoA & L AcoA & L PcoA & R PcoA \\
\hline $\mathrm{F}$ & 48 & 2 & $N$ & 1 & & & & & & 1 \\
\hline $\mathrm{F}$ & 76 & 2 & $N$ & & & I & & 1 & & \\
\hline $\mathrm{F}$ & 67 & 2 & $Y$ & & & & & & I & I \\
\hline $\mathrm{F}$ & 60 & 2 & $Y$ & & & I & & 1 & & \\
\hline $\mathrm{F}$ & 60 & 2 & $\mathrm{~N}$ & & & & 1 & & I & \\
\hline $\mathrm{F}$ & 56 & 2 & $\mathrm{~N}$ & & & I & & & & I \\
\hline \multirow[t]{2}{*}{$F$} & 67 & 3 & $Y$ & & I & & & & I & I \\
\hline & & & Subtotal & 1 & I & 3 & I & 2 & 3 & 4 \\
\hline
\end{tabular}

Abbreviations: L, right; R, right; ICA, internal carotid artery (including any aneurysm located in the intracranial portion of ICA); MCA, middle cerebral artery; AcoA, anterior communicating artery; PcoA, posterior communicating artery.

classified PcoA as part of the anterior circulation. A high proportion of ruptured aneurysms were located in the PcoA (36.6\%) or AcoA (25.7\%), which is similar to the pattern reported in the Western and Japanese populations. ${ }^{8,11,21}$ This finding is also consistent with previous reports from Hong Kong and Taiwan. ${ }^{16-18}$ This could be explained by the relatively smaller thickness and diameter of the PcoA and AcoA, which limits the size of the aneurysm at the time of rupture. It is likely that of all aneurysms, midline lesions are at greater risk of rupture at a smaller size than are more laterally situated aneurysms. ${ }^{11}$ Our previous data showed more cases of AcoA than PcoA aneurysm rupture before the age of 50 years, but more cases of PcoA than AcoA aneurysm rupture after the age of 50 years..$^{19}$ However, we did not find this pattern in the current study (data not shown). Interestingly, our present study showed more cases of AcoA aneurysm on the left side ( 53 [Left side] $/ 16$ [Right side] $=3.31$, $P<0.001)$ and more cases of PcoA aneurysm on the right side (54 [Right side]/44[Left side] $=1.23, P>0.05$ ). Data from our previous study were similar, with AcoA aneurysm having a left to right ratio of $210 / 104=2.02(P<0.001)$ and PcoA aneurysm a right to left ratio of 197:177=1.11 ( $P=0.301)$. Although the higher incidence of PcoA aneurysm in the right side was not statistically significant, it is interesting that this tendency was observed in both studies.

The prevalence of multiple aneurysms was only $2.7 \%$ in the current series, and much lower than the $14.57 \%$ in our previous report; ${ }^{19}$ it is also lower than previous reports of $17 \%$ in the Hong Kong population and $15 \%$ in the Japanese population. ${ }^{15,18}$ Literature for Western populations reports figures of $30 \%-40 \%{ }^{30-33}$ Female sex is considered a risk factor for multiple aneurysms, ${ }^{30,32}$ and in this study, the seven cases with multiple aneurysms were all females. PcoA was the most common site for mirrored ruptured cerebral aneurysms, which is similar to our previous report. ${ }^{19}$ However, this is different from a report by Meissner et al who found that the most common sites of mirror aneurysms were the middle cerebral artery followed by the noncavernous internal carotid artery. ${ }^{34}$

There are many limitations in this study. First, it was a retrospective analysis of medical records from a single hospital and its sample size was relatively small, so its results should be viewed with this in mind. Second, the size of the ruptured aneurysm was not available for all patients. Also, in multiple aneurysm cases, the specific aneurysm for the rupture could not be 'confirmed'. Screening for asymptomatic cerebral aneurysms is not routinely undertaken in China. Our study examined ruptured aneurysms in a population with an unknown number of unruptured aneurysms. Further, we do not know how many patients with ruptured aneurysms did not seek medical attention. However, we had direct access to the records of a previous study cohort in the Chinese population, ${ }^{19}$ and the same analytic approach was taken, so direct comparisons were feasible. Overall, the results in the present study confirmed the results of our recent paper. ${ }^{19}$ Epidemiological differences have been noted between Chinese patients, Caucasian patients, and Japanese patients, which could potentially be due to differences in ethnicity, the specific cohorts included in the studies, and the size of the study cohorts, as well as in patterns of seeking treatment.

In conclusion, the results of the present study support our previous findings in the Chinese population showing: the female predominance is weaker in the younger age group; a tendency for males to have a slightly larger aneurysm size than females; ruptured aneurysms are mostly in the size range of 2-5 $\mathrm{mm}$; a high proportion of ruptured aneurysms from the PcoA and AcoA; and a higher incidence of AcoA aneurysm rupture on the left side than on the right side, with a higher incidence of PcoA aneurysm rupture on the right side than on the left side. In contrast with other reports, the prevalence of multiple aneurysms was only $2.7 \%$ in this cohort. 


\section{Disclosure}

The authors report no conflicts of interest in this work.

\section{References}

1. Pakarinen S. Incidence, aetiology, and prognosis of primary subarachnoid haemorrhage. A study based on 589 cases diagnosed in a defined urban population during a defined period. Acta Neurol Scand. 1967;43: Suppl 29:1-28.

2. Phillips LH 2nd, Whisnant JP, O'Fallon WM, Sundt TM Jr. The unchanging pattern of subarachnoid hemorrhage in a community. Neurology. 1980;30:1034-1040.

3. de Rooij NK, Linn FH, van der Plas JA, Algra A, Rinkel GJ. Incidence of subarachnoid haemorrhage: a systematic review with emphasis on region, age, gender and time trends. J Neurol Neurosurg Psychiatry. 2007;78:1365-1372.

4. Cioffi F, Pasqualin A, Cavazzani P, Da Pian R. Subarachnoid haemorrhage of unknown origin: clinical and tomographical aspects. Acta Neurochir (Wien). 1989;97:31-39.

5. Rinkel GJ, Djibuti M, Algra A, Van Gijn J. Prevalence and risk of rupture of intracranial aneurysms: a systematic review. Stroke. 1998;29: 251-256.

6. Vernooij MW, Ikram MA, Tanghe HL, et al. Incidental findings on brain MRI in the general population. N Engl J Med. 2007;357:1821-1828.

7. Dickey P, Nunes J, Bautista C, Goodrich I. Intracranial aneurysms: size, risk of rupture, and prophy lactic surgical treatment. Conn Med. 1994; 58:583-586.

8. Forget TR Jr, Benitez R, Veznedaroglu E, et al. A review of size and location of ruptured intracranial aneurysms. Neurosurgery. 2001;49: $1322-1325$

9. Juvela S. Risk factors for multiple intracranial aneurysms. Stroke. 2000;31:392-397.

10. [No authors listed]. Unruptured intracranial aneurysms - risk of rupture and risks of surgical intervention. International Study of Unruptured Intracranial Aneurysms Investigators. N Engl J Med. 1998; 339:1725-1733.

11. Weir B, Disney L, Karrison T. Sizes of ruptured and unruptured aneurysms in relation to their sites and the ages of patients. J Neurosurg. 2002;96:64-70.

12. Clarke M. Systematic review of reviews of risk factors for intracranial aneurysms. Neuroradiology. 2008;50:653-664.

13. Ujiie H, Sato K, Onda H, et al. Clinical analysis of incidentally discovered unruptured aneurysms. Stroke. 1993;24:1850-1856.

14. Nakagawa $T$, Hashi $K$. The incidence and treatment of asymptomatic, unruptured cerebral aneurysms. J Neurosurg. 1994;80:217-223.

15. Kaminogo M, Yonekura M, Shibata S. Incidence and outcome of multiple intracranial aneurysms in a defined population. Stroke. 2003;34: $16-21$.

16. So SC, Ngan H, Ong GB. Intracranial aneurysms causing subarachnoid haemorrhage in the Chinese. Surg Neurol. 1979;12:319-321.

17. Howng SL, Hung TP, Kwan AL, Lin CL. [Intracranial aneurysm in Taiwan]. J Formos Med Assoc. 1995;94 Suppl 2:S73-S80. Chinese.

18. Lai HP, Cheng KM, Yu SC, et al. Size, location, and multiplicity of ruptured intracranial aneurysms in the Hong Kong Chinese population with subarachnoid haemorrhage. Hong Kong Med J. 2009;15:262-266.
19. Zhao L, Zhang L, Zhang X, Li Z, Tian L, Wang YX. An analysis of 1,256 cases of sporadic ruptured cerebral aneurysm in a single Chinese institution. PLoS One. 2014;9:e85668.

20. Wang YX. Advance modern medicine with clinical case reports. Quant Imaging Med Surg. 2014;4:439-443.

21. Aarhus M, Helland CA, Wester K. Differences in anatomical distribution, gender, and sidedness between ruptured and unruptured intracranial aneurysms in a defined patient population. Acta Neurochir (Wien). 2009; 151:1569-1574.

22. Osawa M, Hongo K, Tanaka Y, Nakamura Y, Kitazawa K, Kobayashi S. Results of direct surgery for aneurysmal subarachnoid haemorrhage: outcome of 2,055 patients who underwent direct aneurysm surgery and profile of ruptured intracranial aneurysms. Acta Neurochir (Wien). 2001;143:655-663.

23. Baumann F, Khan N, Yonekawa Y. Patient and aneurysm characteristics in multiple intracranial aneurysms. Acta Neurochir Suppl. 2008;103: 19-28.

24. Ohashi Y, Horikoshi T, Sugita M, Yagishita T, Nukui H. Size of cerebral aneurysms and related factors in patients with subarachnoid hemorrhage. Surg Neurol. 2004;61:239-245.

25. Roessler K, Cejna M, Zachenhofer I. Aneurysmatic subarachnoidal haemorrhage: incidence and location of small ruptured cerebral aneurysms - a retrospective population-based study. Wien Klin Wochenschr. 2011;123:444-449.

26. Kassell NF, Torner JC. Size of intracranial aneurysms. Neurosurgery. 1983;12:291-297

27. Mozoi K, Kwak R, Sakamoto T, et al. Angiographic study of intracranial saccular aneurysms: with particular reference to their size and shape. In: Suzuki J, editor. Cerebral Aneurysms. Experiences with 1,000 Directly Operated Cases. Tokyo, Japan: Neuron Publishing Co; 1979.

28. Shiue I, Arima H, Hankey GJ, Anderson CS. Location and size of ruptured intracranial aneurysm and serious clinical outcomes early after subarachnoid hemorrhage: a population-based study in Australasia. Cerebrovasc Dis. 2011;31:573-579.

29. Clarke G, Mendelow AD, Mitchell P. Predicting the risk of rupture of intracranial aneurysms based on anatomical location. Acta Neurochir (Wien). 2005;147:259-263.

30. Juvela S, Porras M, Poussa K. Natural history of unruptured intracranial aneurysms: probability of and risk factors for aneurysm rupture. J Neurosurg. 2000;93:379-387.

31. Qureshi AI, Suarez JI, Parekh PD, et al. Risk factors for multiple intracranial aneurysms. Neurosurgery. 1998;43:22-26.

32. Ellamushi HE, Grieve JP, Jager HR, Kitchen ND. Risk factors for the formation of multiple intracranial aneurysms. J Neurosurg. 2001;94: 728-732.

33. Salunke P, Malik V, Yogesh N, Khandelwal NK, Mathuriya SN. Mirrorlike aneurysms of proximal anterior cerebral artery: report of a case and review of literature. Br J Neurosurg. 2010;24:686-687.

34. Meissner I, Torner J, Huston J 3rd, et al. Mirror aneurysms: a reflection on natural history. J Neurosurg. 2012;116:1238-1241.
Neuropsychiatric Disease and Treatment

\section{Publish your work in this journal}

Neuropsychiatric Disease and Treatment is an international, peerreviewed journal of clinical therapeutics and pharmacology focusing on concise rapid reporting of clinical or pre-clinical studies on a range of neuropsychiatric and neurological disorders. This journal is indexed on PubMed Central, the 'PsycINFO' database and CAS,

\section{Dovepress}

and is the official journal of The International Neuropsychiatric Association (INA). The manuscript management system is completely online and includes a very quick and fair peer-review system, which is all easy to use. Visit http://www.dovepress.com/testimonials.php to read real quotes from published authors. 